\title{
Kinetics and Mechanism of the Oxidation of Naphthol Green B by Peroxydisulphate Ion in Aqueous Acidic Medium
}

\author{
B. Myek, ${ }^{1}$ S. O. Idris, ${ }^{2}$ and J. F. Iyun ${ }^{2}$ \\ ${ }^{1}$ Department of Basic Research, National Research Institute for Chemical Technology, PMB 1052, Zaria, Kaduna State, Nigeria \\ ${ }^{2}$ Department of Chemistry, Ahmadu Bello University, Zaria, Nigeria
}

Correspondence should be addressed to B. Myek; myekbb@yahoo.com

Received 21 October 2013; Revised 21 February 2014; Accepted 24 February 2014; Published 25 March 2014

Academic Editor: Alfonso Castiñeiras

Copyright (c) 2014 B. Myek et al. This is an open access article distributed under the Creative Commons Attribution License, which permits unrestricted use, distribution, and reproduction in any medium, provided the original work is properly cited.

\begin{abstract}
The kinetics of the oxidation of naphthol green $\mathrm{B}\left(\mathrm{NGB}^{3-}\right)$ by peroxydisulphate ion has been carried out in aqueous acidic medium at $\lambda_{\max }$ of $700 \mathrm{~nm}, T=23 \pm 1^{\circ} \mathrm{C}$, and $I=0.50 \mathrm{~mol} \mathrm{dm}^{-3}(\mathrm{NaCl})$. The reaction shows a first-order dependence on oxidant and reductant concentration, respectively. The stoichiometry of the $\mathrm{NGB}-\mathrm{S}_{2} \mathrm{O}_{8}{ }^{2-}$ reaction is $1: 2$. Change in hydrogen ions concentration of the reaction medium has no effect on the rate of the reaction. Added cations and anions decreased the rate of the reaction. The results of spectroscopic and kinetic investigation indicate that no intermediate complex is probably formed in the course of this reaction.
\end{abstract}

\section{Introduction}

Naphthol green B is used in histology to stain collagen. The dye is a lake, in which the mordant metal is ferric iron. However, the iron appears to play no part in its staining ability [1]. Naphthol green B is very soluble in water and has an absorption maximum of $714 \mathrm{~nm}$. As an anion, it acts as an acid dye [2]. Kinetic spectrophotometric method for the determination of cerium (IV) with naphthol green $B$ has been studied [3]. The reaction was monitored spectrophotometrically by measuring the decrease in absorbance of naphthol green $B$ at $710 \mathrm{~nm}$. It was found that the reaction rate is very slow when the temperature is below $60^{\circ} \mathrm{C}$, but the rate of the catalyzed reaction increases rapidly when the reaction temperatures are above $70^{\circ} \mathrm{C}$.

Peroxydisulphate ion is one of the powerful oxidizing agents known $[4,5]$. A large number of investigations have been carried out in the oxidation of metal ions [6,7], metal complex [8,9], and various organic compounds [10] by $\mathrm{S}_{2} \mathrm{O}_{8}{ }^{2-}$. Most electron transfer reactions of $\mathrm{S}_{2} \mathrm{O}_{8}{ }^{2-}$ occur by the outer-sphere mechanism [11-13]. However, reactions with some positively charged metal complexes such as $\mathrm{Fe}(\mathrm{bpy})_{3}{ }^{2+}$, $\mathrm{Fe}(\mathrm{Phen})_{3}{ }^{2+}$, and Os(bpy $)_{3}{ }^{2+}$ occur by both the outer-sphere and the inner-sphere mechanisms $[5,9]$. Except when the reducing agent can be protonated, the redox reaction of
$\mathrm{S}_{2} \mathrm{O}_{8}{ }^{2-}$ was found to be independent of hydrogen ion concentration [14]. Despite its reactions with other compounds, the redox reaction of this oxidant with naphthol green B is scanty.

It is our hope that this investigation will help to gain more insight into the redox reaction of naphthol green $B$ with peroxydisulphate ion.

\section{Materials and Methods}

The chemicals used were of analytical grade and were used without further purification. Standard solution of $\mathrm{NGB}^{3-}$ was prepared by dissolving $0.088 \mathrm{~g}$ in $100 \mathrm{~cm}^{3}$ volumetric flask using distilled water. Sodium peroxydisulphate solution was prepared by dissolving known quantities in distilled water. All other reagents used were of analytical grade.

The stoichiometry of the reaction was determined spectrophotometrically using the mole ratio method by keeping the concentration of the dye constant at $4.0 \times 10^{-5} \mathrm{~mol} \mathrm{dm}^{-3}$, $\left[\mathrm{H}^{+}\right]=1.0 \times 10^{-4} \mathrm{~mol} \mathrm{dm}{ }^{-3}, I=0.50, \lambda_{\max }=700 \mathrm{~nm}$, $T=23 \pm 1^{\circ} \mathrm{C}$, and $\left[\mathrm{S}_{2} \mathrm{O}_{8}{ }^{2-}\right]=(0.08-1.4) \times 10^{-4} \mathrm{~mol} \mathrm{dm}^{-3}$. The stoichiometry was evaluated from the plot of absorbance versus [reductant]/[oxidant] after the reaction had reached completion by the observation of a steady zero absorbance value over a period of two days. 
TABLE 1: Pseudo-first-order and second-order rate constants for the reaction of naphthol green $\mathrm{B}_{\text {and }} \mathrm{S}_{2} \mathrm{O}_{8}{ }^{2-}$ at $\left[\mathrm{NGB}^{3-}\right]=4.0 \times 10^{-5} \mathrm{~mol} \mathrm{dm}^{-3}$, $\lambda=700 \mathrm{~nm}$, and $T=23 \pm 1^{\circ} \mathrm{C}$.

\begin{tabular}{|c|c|c|c|c|}
\hline $10^{3}\left[\mathrm{~S}_{2} \mathrm{O}_{8}{ }^{2-}\right], \mathrm{mol} \mathrm{dm}^{-3}$ & $10^{4}\left[\mathrm{H}^{+}\right], \mathrm{mol} \mathrm{dm}^{-3}$ & $10^{1} I, \mathrm{~mol} \mathrm{dm}^{-3}$ & $10^{3} k_{1}, \mathrm{~s}^{-1}$ & $k_{2}, \mathrm{dm}^{3} \mathrm{~mol}^{-1} \mathrm{~s}^{-1}$ \\
\hline 4.8 & 1.0 & 5.0 & 7.30 & 1.52 \\
\hline 5.2 & 1.0 & 5.0 & 8.22 & 1.58 \\
\hline 5.6 & 1.0 & 5.0 & 8.50 & 1.52 \\
\hline 6.0 & 1.0 & 5.0 & 9.39 & 1.57 \\
\hline 6.4 & 1.0 & 5.0 & 9.79 & 1.53 \\
\hline 6.8 & 1.0 & 5.0 & 10.70 & 1.57 \\
\hline 5.6 & 0.1 & 5.0 & 8.39 & 1.50 \\
\hline 5.6 & 0.5 & 5.0 & 8.50 & 1.52 \\
\hline 5.6 & 1.0 & 5.0 & 8.59 & 1.53 \\
\hline 5.6 & 1.5 & 5.0 & 8.82 & 1.58 \\
\hline 5.6 & 2.0 & 5.0 & 8.64 & 1.54 \\
\hline 5.6 & 4.0 & 5.0 & 8.17 & 1.46 \\
\hline 5.6 & 10.0 & 5.0 & 8.64 & 1.54 \\
\hline 5.6 & 1.0 & 0.5 & 17.7 & 3.16 \\
\hline 5.6 & 1.0 & 1.0 & 15.4 & 2.74 \\
\hline 5.6 & 1.0 & 2.0 & 10.10 & 1.80 \\
\hline 5.6 & 1.0 & 5.0 & 8.58 & 1.53 \\
\hline 5.6 & 1.0 & 6.0 & 6.91 & 1.23 \\
\hline 5.6 & 1.0 & 7.0 & 6.14 & 1.10 \\
\hline
\end{tabular}

A Corning Colorimeter Model 252 spectrophotometer was used to follow the decrease in absorbance of the dye at $700 \mathrm{~nm}, T=23 \pm 1^{\circ} \mathrm{C}, I=0.5 \mathrm{~mol} \mathrm{dm}^{-3}(\mathrm{NaCl})$, and $\left[\mathrm{H}^{+}\right]=$ $1.0 \times 10^{-4} \mathrm{~mol} \mathrm{dm}^{-3}(\mathrm{HCl})$. The kinetic runs were conducted under pseudo-first-order conditions with $\left[\mathrm{S}_{2} \mathrm{O}_{8}{ }^{2-}\right]$ in at least 120 -fold excess over $\left[\mathrm{NGB}^{3-}\right]$. The pseudo-first-order plots of $\log \left(A_{t}-A_{\infty}\right)$ versus time were made (where $A_{t}$ and $A_{\infty}$ are the absorbance at time $t$ and at the end of the reaction, resp.). From the slope of the plots, the pseudo-first-order rate constant $\left(k_{1}\right)$ was determined [15].

The effect of acid on the rate of reaction was studied by varying $\left[\mathrm{H}^{+}\right]$in the range $(0.1-10.0) \times 10^{-4} \mathrm{~mol} \mathrm{dm}^{-3}$, while $\left[\mathrm{NGB}^{3-}\right]$ and $\left[\mathrm{S}_{2} \mathrm{O}_{8}{ }^{2-}\right]$ were kept constant at $23 \pm 1^{\circ} \mathrm{C}$ and $I=0.5 \mathrm{~mol} \mathrm{dm}^{-3}(\mathrm{NaCl})$. The range was narrow because acid was stable at such range.

The effect of ionic strength on the rate of the reaction was investigated in the range of $0.05-0.7 \mathrm{~mol} \mathrm{dm}^{-3}(\mathrm{NaCl})$ while the concentrations of other reagents were kept constant at $23 \pm$ $1^{\circ} \mathrm{C}$.

\section{Results and Discussion}

The result of stoichiometric studies reveals that one mole of $\mathrm{NGB}^{3-}$ reacted quantitatively with two moles of $\mathrm{S}_{2} \mathrm{O}_{8}{ }^{2-}$. Hence the overall equation for the reaction is

$$
\mathrm{NGB}^{3-}+2 \mathrm{~S}_{2} \mathrm{O}_{8}{ }^{2-} \longrightarrow \mathrm{SO}_{4}{ }^{2-}+\text { other products }
$$

The presence of $\mathrm{SO}_{4}{ }^{2-}$ was confirmed qualitatively by the addition of $\mathrm{BaCl}_{2}$ followed by $\mathrm{HCl}$ which formed an insoluble white precipitate in excess $\mathrm{HCl}$. Kinetic studies indicated

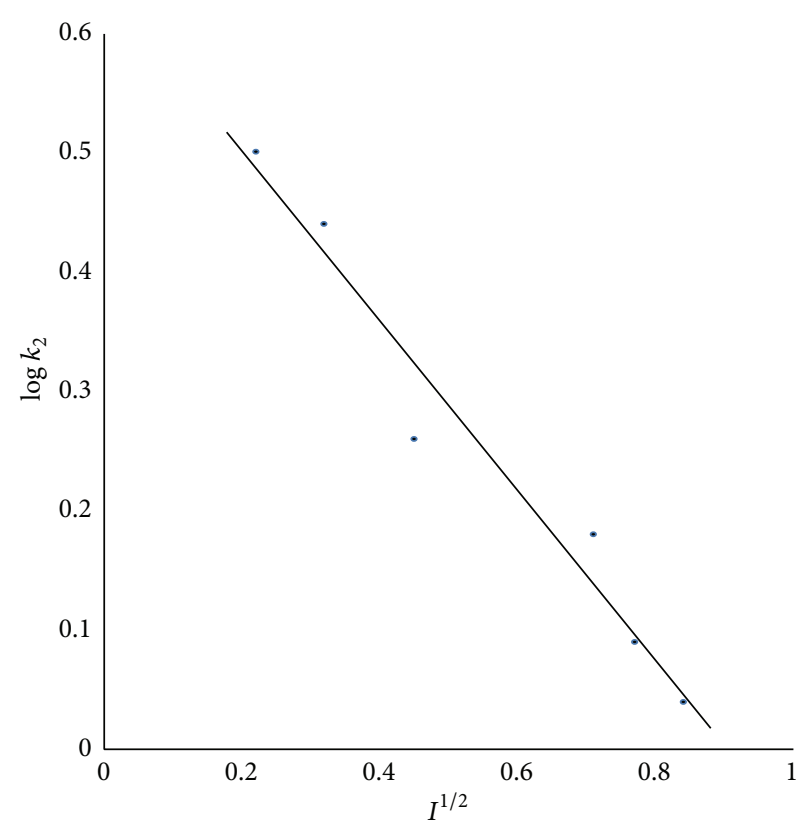

FIGURE 1: Plot of $\log k_{2}$ versus $I^{1 / 2}$ for the redox reaction between naphthol green $\mathrm{B}$ and $\mathrm{S}_{2} \mathrm{O}_{8}{ }^{2-}$ at $\left[\mathrm{NGB}^{3-}\right]=4.0 \times 10^{-5} \mathrm{~mol} \mathrm{dm}{ }^{-3}$, $\left[\mathrm{S}_{2} \mathrm{O}_{8}{ }^{2-}\right]=5.6 \times 10^{-3} \mathrm{~mol} \mathrm{dm}^{-3},\left[\mathrm{H}^{+}\right]=1.0 \times 10^{-4} \mathrm{~mol} \mathrm{dm}^{-3}, I=$ $0.05-0.7 \mathrm{~mol} \mathrm{dm}{ }^{-3}, \lambda=700 \mathrm{~nm}$, and $T=23 \pm 1^{\circ} \mathrm{C}$.

first-order dependence of rate of reaction on $\left[\mathrm{NGB}^{3-}\right]$ and $\left[\mathrm{S}_{2} \mathrm{O}_{8}{ }^{2-}\right]$. Under the experimental conditions employed $k_{2}$ was found to be $1.55 \pm 0.22 \mathrm{dm}^{3} \mathrm{~mol}^{-1} \mathrm{~s}^{-1}$. 


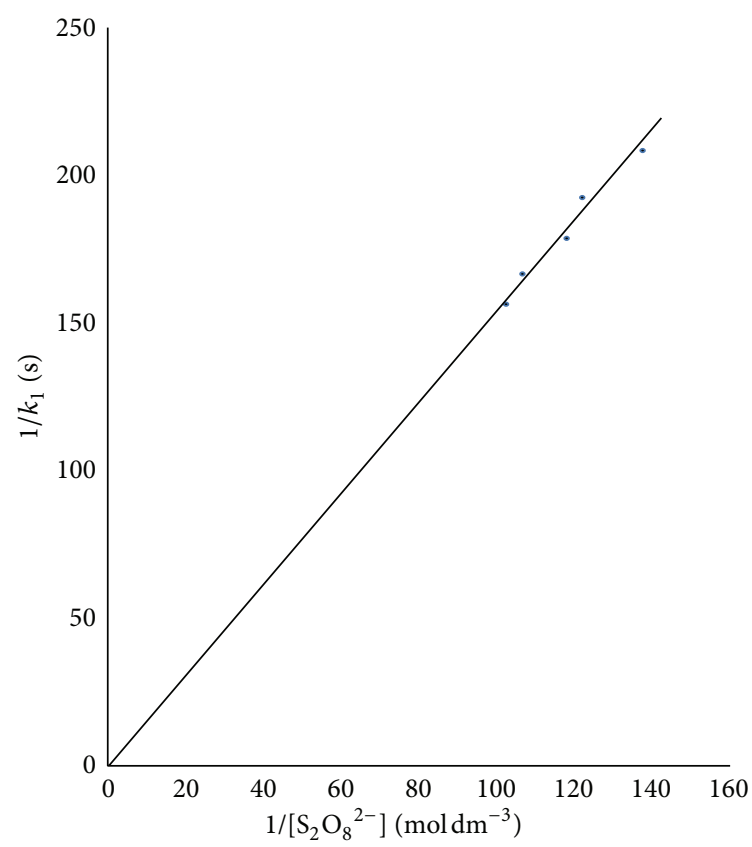

Figure 2: The Michaelis-Menten plot for the redox reaction between naphthol green $\mathrm{B}$ and $\mathrm{S}_{2} \mathrm{O}_{8}{ }^{2-}$ at $[\mathrm{NGB}]=4.0 \times 10^{-5} \mathrm{~mol} \mathrm{dm}^{-3}$, $\left[\mathrm{S}_{2} \mathrm{O}_{8}{ }^{2-}\right]=(4.8-6.8) \times 10^{-3} \mathrm{~mol} \mathrm{dm}{ }^{-3},\left[\mathrm{H}^{+}\right]=1.0 \times 10^{-4} \mathrm{~mol} \mathrm{dm}^{-3}$, $I=0.50 \mathrm{~mol} \mathrm{dm}^{-3}, \lambda=700 \mathrm{~nm}$, and $T=23 \pm 1^{\circ} \mathrm{C}$.

The rate equation for the reaction is

$$
-\frac{d[\mathrm{NGB}]}{d t}=k_{2}\left[\mathrm{NGB}^{3-}\right]\left[\mathrm{S}_{2} \mathrm{O}_{8}{ }^{2-}\right] .
$$

Effect of changes in ionic strength of the reaction medium indicated that the rate constant decreases with increase in ionic strength. This obeyed a negative Bronsted-Debye salt effect [16]. Plot of $\log k_{2}$ against $I^{1 / 2}$ (Figure 1) gave a slope of $-0.71\left(R^{2}=0.96\right)$.

The reaction was found to be independent of $\left[\mathrm{H}^{+}\right]$in the range of $(0.1-10) \times 10^{-4} \mathrm{~mol} \mathrm{dm}{ }^{-3}$ investigated, indicating that the reaction occurs through an acid-independent pathway (Table 1). Similar results have been reported for the redox reaction of $\mathrm{S}_{2} \mathrm{O}_{8}{ }^{2-}$ [17-19]. Added cation and anion inhibited the rate of the reaction (Tables 2 and 3 ). This inhibited effect by the ions suggested that the reaction might be operating via the outersphere mechanism [20].

Spectroscopic evidence and the Michaelis-Menten plot of $1 / k_{1}$ versus $1 / \mathrm{S}_{2} \mathrm{O}_{8}{ }^{2-}$ (Figure 2 ) suggest that intermediates may be unimportant in the rate determining step. Free radical test did not yield gel formation or if present it might be transient.

On the basis of the above findings, the mechanism below is proposed for this reaction.

\section{Reaction Scheme}

The reaction scheme is as follows:

$$
\mathrm{NGB}^{3-}+\mathrm{S}_{2} \mathrm{O}_{8}{ }^{2-} \stackrel{k_{1}}{\longrightarrow} \mathrm{NGB}^{-}+2 \mathrm{SO}_{4}{ }^{2-} \text { slow }
$$

TABLE 2: Rate data for the effect of added cations $\left(\mathrm{Ca}^{2+}\right.$ and $\left.\mathrm{Mg}^{2+}\right)$ on the rate of reaction of naphthol green $\mathrm{B}$ with $\mathrm{S}_{2} \mathrm{O}_{8}{ }^{2-}$ at $\left[\mathrm{NGB}^{3-}\right]$ $=4.0 \times 10^{-5} \mathrm{~mol} \mathrm{dm}^{-3},\left[\mathrm{~S}_{2} \mathrm{O}_{8}{ }^{2-}\right]=5.6 \times 10^{-3} \mathrm{~mol} \mathrm{dm}^{-3},\left[\mathrm{H}^{+}\right]=1.0 \times$ $10^{-4} \mathrm{~mol} \mathrm{dm}^{-3}, I=0.50 \mathrm{~mol} \mathrm{dm}{ }^{-3}, \lambda=700 \mathrm{~nm}$, and $T=23 \pm 1^{\circ} \mathrm{C}$.

\begin{tabular}{cccc}
\hline Ion & $10^{3}\left[\right.$ ion] $\mathrm{mol} \mathrm{dm}^{-3}$ & $10^{3} k_{1}, \mathrm{~s}^{-1}$ & $k_{2}, \mathrm{dm}^{3} \mathrm{~mol}^{-1} \mathrm{~s}^{-1}$ \\
\hline & 1.0 & 8.25 & 1.47 \\
$\mathrm{Ca}^{2+}$ & 10.0 & 7.84 & 1.40 \\
& 20.0 & 7.30 & 1.30 \\
& 60.0 & 7.05 & 1.26 \\
& 80.0 & 6.91 & 1.23 \\
& 200.0 & 5.57 & 0.99 \\
\hline \multirow{3}{*}{$\mathrm{Mg}^{2+}$} & 1.0 & 7.42 & 1.33 \\
& 5.0 & 5.59 & 1.00 \\
& 10.0 & 4.48 & 0.80 \\
& 20.0 & 4.11 & 0.73 \\
& 80.0 & 3.65 & 0.65 \\
& 200.0 & 2.65 & 0.47 \\
\hline
\end{tabular}

TABLE 3: Rate data for the effect of added anions $\left(\mathrm{SO}_{4}{ }^{2-}\right.$ and $\mathrm{CH}_{3} \mathrm{COO}^{-}$) on the rate of reaction of naphthol green $\mathrm{B}$ with $\mathrm{S}_{2} \mathrm{O}_{8}{ }^{2-}$ at $\left[\mathrm{NGB}^{3-}\right]=4.0 \times 10^{-5} \mathrm{~mol} \mathrm{dm}^{-3},\left[\mathrm{~S}_{2} \mathrm{O}_{8}{ }^{2-}\right]=5.6 \times 10^{-3} \mathrm{~mol} \mathrm{dm}^{-3}$, $\left[\mathrm{H}^{+}\right]=1.0 \times 10^{-4} \mathrm{~mol} \mathrm{dm}^{-3}, I=0.50 \mathrm{~mol} \mathrm{dm}{ }^{-3}, \lambda=700 \mathrm{~nm}$, and $T$ $=23 \pm 1^{\circ} \mathrm{C}$.

\begin{tabular}{lccc}
\hline Ion & $10^{3}[$ ion $], \mathrm{mol} \mathrm{dm}^{-3}$ & $10^{3} k_{1}, \mathrm{~s}^{-1}$ & $k_{2}, \mathrm{dm}^{3} \mathrm{~mol}^{-1} \mathrm{~s}^{-1}$ \\
\hline & 1.0 & 7.26 & 1.30 \\
$\mathrm{SO}_{4}{ }^{2-}$ & 5.0 & 6.60 & 1.18 \\
& 10.0 & 5.60 & 1.00 \\
& 20.0 & 5.32 & 0.95 \\
& 80.0 & 3.26 & 0.58 \\
\hline & 1.0 & 6.45 & 1.15 \\
$\mathrm{CH}_{3} \mathrm{COO}^{-}$ & 2.0 & 4.19 & 0.75 \\
& 3.0 & 2.88 & 0.51 \\
& 4.0 & 2.69 & 0.48 \\
& 5.0 & 1.77 & 0.32 \\
\hline
\end{tabular}

$$
\begin{gathered}
\mathrm{NGB}^{-}+\mathrm{S}_{2} \mathrm{O}_{8}{ }^{2-} \stackrel{k_{2}}{\longrightarrow} \mathrm{NGB}+\mathrm{S}_{2} \mathrm{O}_{8}{ }^{3-} \\
\mathrm{S}_{2} \mathrm{O}_{8}{ }^{3-} \stackrel{k_{3}}{\longrightarrow} \mathrm{SO}_{4}{ }^{2-}+\mathrm{SO}_{4}{ }^{--} \\
\mathrm{SO}_{4}{ }^{--}+\mathrm{H}_{2} \mathrm{O} \stackrel{k_{4}}{\longrightarrow} \mathrm{SO}_{4}{ }^{2-}+\mathrm{OH}^{\bullet}+\mathrm{H}^{+} \\
\mathrm{H}^{+}+\mathrm{OH}^{\bullet}+\mathrm{SO}_{4}{ }^{--} \stackrel{k_{5}}{\longrightarrow} \mathrm{H}_{2} \mathrm{SO}_{5} \\
\text { Rate }=k_{1}\left[\mathrm{NGB}^{3-}\right]\left[\mathrm{S}_{2} \mathrm{O}_{8}{ }^{2-}\right]
\end{gathered}
$$

Equation (8) is analogous to (2) where $k_{2}=k_{1}$.

\section{Conclusion}

The redox reaction of naphthol green " $\mathrm{B}$ " and peroxydisulphate ions in aqueous acidic medium showed a stoichiometry of $1: 2$; a first order was observed for $\mathrm{NGB}^{3-}$ and $\mathrm{S}_{2} \mathrm{O}_{8}{ }^{2-}$ ions, respectively. The rate constant decreases with increase in 
ionic strength and the reaction was found to be independent of $\left[\mathrm{H}^{+}\right]$. Spectroscopic evidence and the Michaelis-Menten plot of $1 / k_{1}$ versus $1 / \mathrm{S}_{2} \mathrm{O}_{8}{ }^{2-}$ suggest that intermediates may be unimportant in the rate determining step. Polymerization test suggests the absence of free radicals in the reaction medium. Based on the above results, it is proposed that the reaction most probably operates through the outer-sphere mechanism.

\section{Conflict of Interests}

The authors declare that there is no conflict of interests regarding the publication of this paper.

\section{References}

[1] G. Edward, Synthesis Dyes in Biology, Medicine and Chemistry, Academic Press, London, UK, 1971.

[2] B. Myek, S. O. Idris, and J. F. Iyun, "Kinetics of the oxidation of naphthol green B by periodate ion in aqueous hydrochloric acid medium," International Journal of Modern Chemistry, vol. 5, no. 2, pp. 127-135, 2013.

[3] Y. Liu and P. Wang, "Kinetic spectrophotometric method for the determination of cerium(IV) with naphthol green B," Rare Metals, vol. 28, no. 1, pp. 5-8, 2009.

[4] J. W. L. Fordham and H. Leverne Williams, "The persulfateiron(II) initiator system for free radical polymerizations," Journal of The American Chemical Society, vol. 73, no. 10, pp. 48554859, 1951.

[5] D. H. Irvine, "441. The oxidation of the trisdipyridylosmium(II) ion by the peroxydisulphate ion in aqueous solution," Journal of the Chemical Society (Resumed), pp. 2166-2170, 1958.

[6] D. M. Yost and H. H. Clausen, "Reduction of peroxysulfate by vanadyl ion with silver ion as catalyst," Journal of the American Chemical Society, vol. 53, no. 9, pp. 3349-3354, 1931.

[7] K. Y. Gupta and D. D. Misra, "The silver ion catalyses oxidation of arsenous acid by $\mathrm{S}_{2} \mathrm{O}_{8}^{2-}$," Bulletin of the Chemical Society of Japan, vol. 32, pp. 1306-1309, 1959.

[8] R. W. Chlebeck and N. W. Lister, "Reaction between alkali metal ferrocyanides and peroxydisulphate in aqueous," Canadian Journal of Chemistry, vol. 45, pp. 2411-2418, 1967.

[9] S. Raman and J. H. C. Brubakar, "The kinetics of the oxidation of substituted 2, 2' -bipyridine and 1, 10-phenanthroline complexes of iron (II), with $\mathrm{S}_{2} \mathrm{O}_{8}^{2-}$ ion," Journal of Inorganic and Nuclear Chemistry, vol. 31, pp. 1091-1201, 1969.

[10] S. S. Gupta and Y. K. Gupta, "Kinetics and mechanism of the iron(III)-catalyzed oxidation of hydrazine with peroxydisulfate in acid medium," Inorganic Chemistry, vol. 20, no. 6, pp. 17481751, 1981.

[11] D. E. Pennington and A. Haim, "Kinetics and mechanism of the chromium(II)-catalyzed substitution of iodide ion in the iodopentaaquochromium(III) ion by water and by fluoride, chloride, and bromide ions," Inorganic Chemistry, vol. 6, no. 12, pp. 2138-2146, 1967.

[12] K. Ohashi, H. E. Matsuzama, and Yamamato, "The kinetics study of the oxidation reaction of tris- $\left(2,2^{\prime}\right.$-bypyridine $)$ Cobalt (II) ion and ethylenediamine-N, N, $\mathrm{N}^{\prime}$, N'tetraacetate(II) ion by $\mathrm{S}_{2} \mathrm{O}_{8}^{2-}$, Bulletin of the Chemical Society of Japan, vol. 49, no. 9, pp. 2440-2442, 1976.

[13] G. A. Ayoko, J. F. Iyun, and I. F. El-Idris, "Electron transfer at tetrahedral cobalt(II), part III: kinetics of copper(II) ion catalysed reduction of periodate," Transition Metal Chemistry, vol. 17, no. 5, pp. 423-425, 1992.

[14] K. Y. Gupta and S. Ghosh, "Hydrogen ion dependence of the oxidation of iron(II) with peroxydisulphate in acidic perchlorate solutions," Inorganic Chemistry, vol. 20, pp. 434-439, 1959.

[15] Y. Mohammed, J. F. Iyun, and S. O. Idris, "Kinetic approach to the mechanism of the redox reaction of malachite green and permanganate ion in aqueous acidic medium," African Journal of Pure and Applied Chemistry, vol. 3, no. 12, pp. 269-274, 2009.

[16] G. Adefikayo Ayoko, J. Femi Iyun, and I. Faskari El-Idris, "Electron transfer at tetrahedral cobalt(II), part II. Kinetics of silver(I) ion catalyzed reduction of peroxydisulphate," Transition Metal Chemistry, vol. 17, pp. 46-49, 1992.

[17] S. S. Gupta and Y. K. Gupta, "Hydrogen ion dependence of the oxidation of iron(II) with peroxydisulphate in acidic perchlorate solutions," Inorganic Chemistry, vol. 20, pp. 434439, 1981.

[18] P. Banerjee and P. M. Pujara, "The kinetics of oxidation of $\mathrm{N}(2-$ hydroxyl)ethylenediamminetetraacetatecobaltate(II) by $\mathrm{S}_{2} \mathrm{O}_{8}^{2-}$ in aqueous acidic solution," Transition Metal Chemistry, vol. 6, pp. 47-54, 1981.

[19] P. S. V. Rao, P. S. N. Murty, and L. A. N. Murty, "Kinetic and mechanism of indigo carmine with peroxydisulphate," Journal of the Chemical Society, vol. 60, p. 1180, 1978.

[20] T. J. Mayer and H. Taube, Comprehensive Coordination Chemistry: The Synthesis, Reaction, Properties and Application of Coordination Compounds, Pergamon Press, London, UK, 1987. 

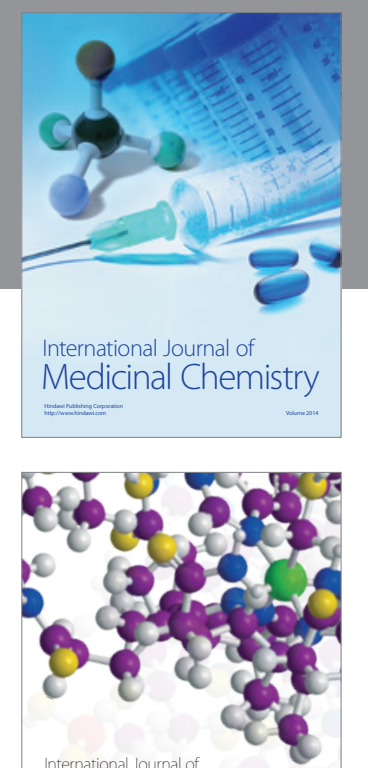

\section{Carbohydrate} Chemistry

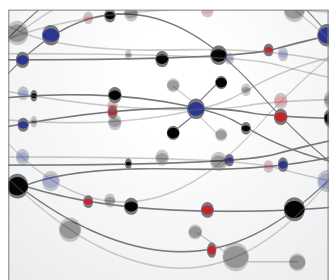

The Scientific World Journal
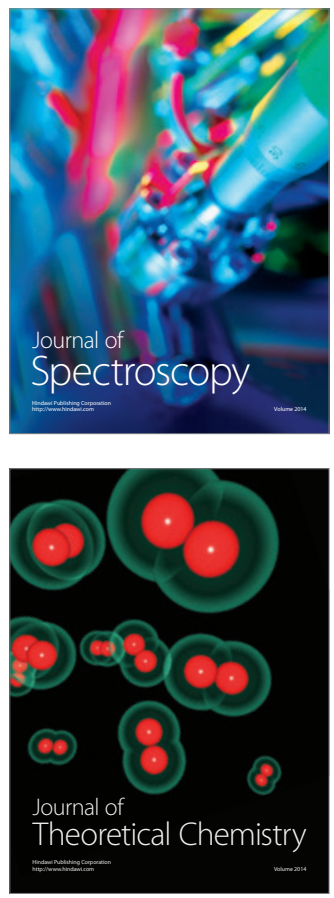
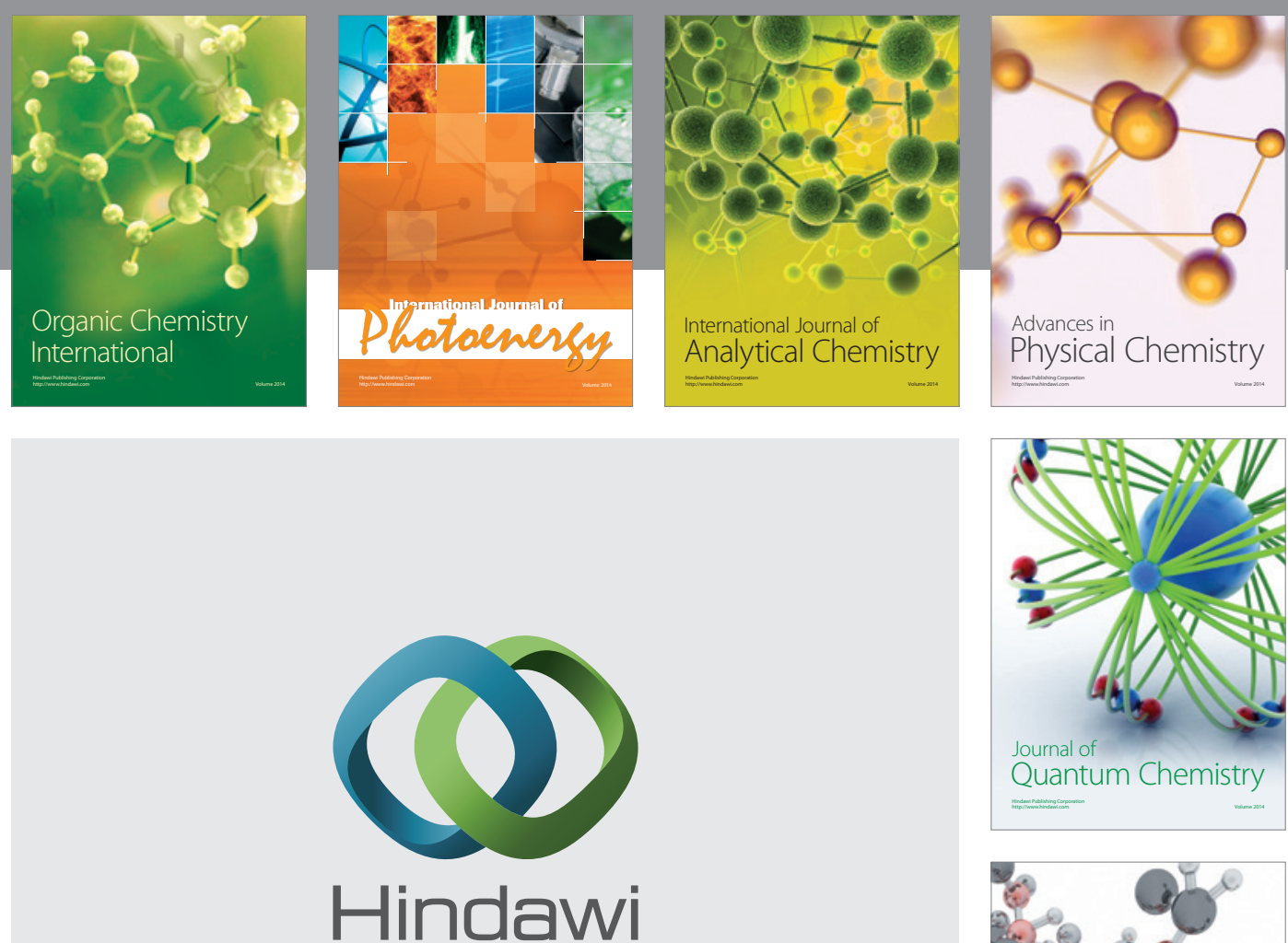

Submit your manuscripts at

http://www.hindawi.com

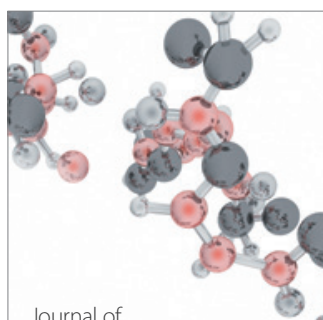

Analytical Methods

in Chemistry

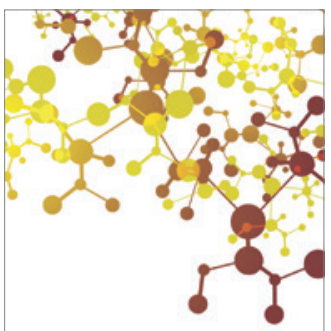

Journal of

Applied Chemistry

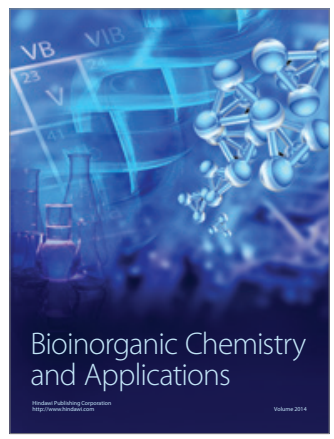

Inorganic Chemistry
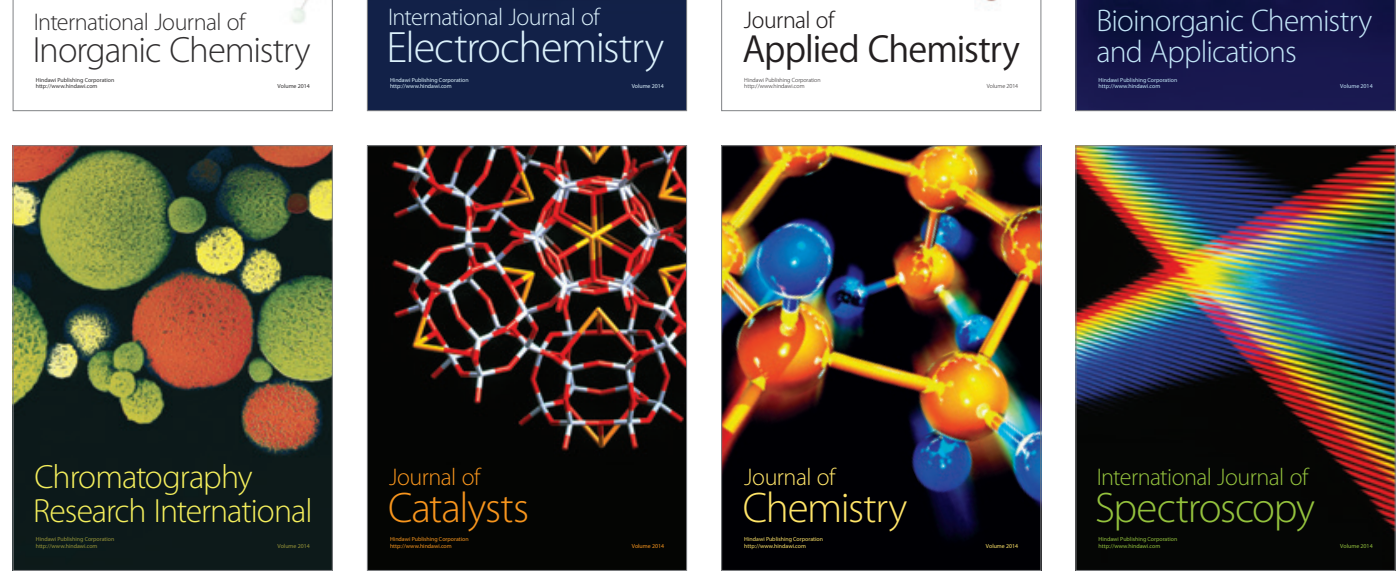